\title{
Controlling Localization and Excretion of Nanoparticles by Click Modification of the Surface Chemical Structures inside Living Cells
}

\section{$\operatorname{AUTHOR}(\mathrm{S})$ :}

Ito, Takeo; Nakamura, Takuma; Kusaka, Eriko; Kurihara, Ryohsuke; Tanabe, Kazuhito

\section{CITATION:}

Ito, Takeo ...[et al]. Controlling Localization and Excretion of Nanoparticles by Click Modification of the Surface Chemical Structures inside Living Cells. ChemPlusChem 2015, 80(5): 796-799

\section{ISSUE DATE:}

2015-03-17

URL:

http://hdl.handle.net/2433/198285

\section{RIGHT:}

This is the peer reviewed version of the following article: Ito, T., Nakamura, T., Kusaka, E., Kurihara, R. and Tanabe, K. (2015), Controlling Localization and Excretion of Nanoparticles by Click Modification of the Surface Chemical Structures inside Living Cells. ChemPlusChem, 80: 796?799., which has been published in final form at

http://dx.doi.org/10.1002/cplu.201402436. This article may be used for non-commercial purposes in accordance with Wiley Terms and Conditions for Self-Archiving.; 許諾条件により本文ファイルは2016-03-17に公開.; この論文は出版社版 でありません。引用の際には出版社版をご確認ご利用ください。; This is not the published version. Please cite only the published version. 
Controlling Localization and Excretion of Nanoparticles by Click Modification of the Surface Chemical Structures inside Living Cells**

Takeo Ito, ${ }^{*}$ Takuma Nakamura, Eriko Kusaka, Ryohsuke Kurihara, and Kazuhito Tanabe*

[*] Dr. Takeo Ito, Mr. Takuma Nakamura, Ms. Eriko Kusaka, Dr. Ryohsuke Kurihara, Dr. Kazuhito Tanabe.

Department of Energy and Hydrocarbon Chemistry

Graduate School of Engineering, Kyoto University

Kyoto Daigaku Katsura, Nishikyo-ku, Kyoto 615-8510, JAPAN

E-mail: takeoito.kyoto@gmail.com; tanabeka@scl.kyoto-u.ac.jp

[**] This work was supported by Grant-in-Aid for Challenging Exploratory Research and the Program for Fostering Regional Innovation “Kyoto Environmental Nanotechnology Cluster” from the Ministry of Education, Culture, Sports, Science and Technology (MEXT) of Japan.

Supporting information for this article is given via a link at the end of the document.

Keywords: click chemistry $\bullet$ exocytosis $\bullet$ intracellular behavior $\bullet$ nanoparticles $\bullet$ phospholipids

Abstract: We conducted surface modification of silica nanoparticles (SiNPs) inside living cells by using the copper-free bioorthogonal click reaction to evaluate the effects of surface chemical structures on dynamic behaviors and excretion of SiNPs. The results demonstrated the spatial translocation of intracellular SiNPs to the plasma membrane upon surface modification in situ with phospholipids. Moreover, we found that the extent and kinetics of excretion of the SiNPs from inside 
the cell are enhanced by the modification.

Synthetic nanoparticles (NPs) engineered for administration into the body have great potential for a wide range of biological applications, such as tools for bioimaging, diagnostics, and tissue- and cell-specific drug delivery systems (DDS). ${ }^{[1-6]}$ Previous in vitro studies have demonstrated that synthetic NPs could be incorporated into living cells mainly through endocytotic pathways depending on their size, shape, and surface charge ${ }^{[7-10]}$ Furthermore, the surface chemical structures of the NPs provide another dimension of physical control that can be refined toward the specific tailoring of function. ${ }^{[11,12]}$

So far, it has been demonstrated that NPs could be delivered to specific targets in living cells by introducing various targeting chemical structures onto their surfaces. ${ }^{[13-15]}$ However, in some cases incorporated NPs accumulate in cells for unfavorably long periods, causing various toxic effects. ${ }^{[16-19]}$ Thus, for the application of engineered NPs as DDS or imaging materials, it is desirable to control the dynamic behavior of the NPs so as to promote their excretion from the cells.

In the current study, we examined the surface chemical modification of NPs in situ to control their intracellular localization. In this way, excretion of NPs from living cells can be accelerated. Surface modification of NPs has been achieved by using highly bioorthogonal click chemistry, and the strain-promoted azide-alkyne cycloaddition is a promising method for with which to accomplish such modification. ${ }^{[20-25]}$ We synthesized a lipid azide that was expected to enhance the affinity of NPs toward plasma membrane after modification in situ, and we have investigated the influence of surface chemical structure on the rate of excretion of the NPs.

We adopted the Cu-free strain-promoted cycloaddition between dibenzocyclooctyne (DBCO) and azido compounds developed by Boons et al. $^{[23]}$ to achieve surface modification of silica 
nanoparticles (SiNPs) in situ in living cells. Fluorescent SiNPs show stable and bright luminescence, which allows their intracellular behavior to be easily monitored. Tetraethoxyorthosilicate (TEOS) and a fluorescein derivative were mixed and hydrolyzed in ammonia solution to afford monodispersed fluorescent SiNPs (Supporting Information). ${ }^{[26,27]} 3$-Aminopropyltriethoxysilane was added to a solution of fluorescent SiNPs in dimethyl sulfoxide (DMSO) to give amino-modified fluorescent SiNPs (SiNP-PEG-NH 2 ). The surfaces of the fabricated NPs were modified with terminally aminated polyethylene glycol (NHS-PEG-NH $\mathrm{NH}_{2}$ (MW 5000) to improve their hydrophilicity. The number of amine moieties per particle was estimated to be $4.1 \times 10^{4}$ by the Fmoc quantification method. ${ }^{[28,29]}$ Finally, the DBCO structure was introduced onto the surface of the SiNPs to afford clickable fluorescent SiNPs (SiNP-PEG-DBCO) (Scheme 1) with a size of $70 \pm 7$ nm (Figure S1, Supporting Information). DBCO modification of the SiNPs induced no toxic effects toward human lung adenocarcinoma A549 cells (Figure S2, Supporting Information). To track the intracellular localization of the synthesized NPs, fluorescence microscope images of A549 cells were obtained upon exposure to SiNP-PEG-DBCO (Figure S3, Supporting Information). SiNPs were mainly observed in lysosomes upon intracellular uptake, and then they were gradually excreted from the cells, although some accumulated inside the cells even after $24 \mathrm{~h}$.

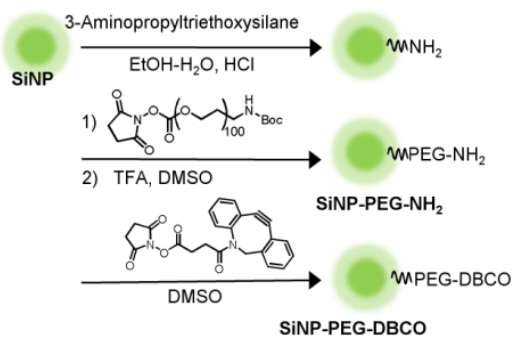

Scheme 1. Synthesis of DBCO-coated SiNPs (SiNP-PEG-DBCO).

To examine the click reactivity of the synthesized SiNP-PEG-DBCO toward azido compounds, azido-terminated cyanine 3 dye $\left(\mathrm{N}_{3}-\mathrm{Cy} 3\right)$ was incubated with either SiNP-PEG-DBCO or 
DBCO-uncoated SiNPs, and then the fluorescence spectra of the resulting SiNPs were measured (Figure S4, Supporting Information). DBCO-uncoated SiNPs showed maximum fluorescence at 520 $\mathrm{nm}$, whereas SiNP-PEG-DBCO showed additional maximum fluorescence at $570 \mathrm{~nm}$ due to fluorescence resonance energy transfer (FRET) from the photoexcited fluorescein in SiNPs to Cy3, suggesting that $\mathrm{N}_{3}-\mathrm{Cy} 3$ was efficiently coupled to DBCO on the surface of SiNPs. In addition, click modification by $\mathrm{N}_{3}-\mathrm{Cy} 3$ in living cells was confirmed by adding the dye to A549 cells that had SiNP-PEG-DBCO incorporated inside the cells (Figure 1). FRET was observed for the SiNP-PEG-DBCO-treated cells (Figure 1e) but not for the SiNP-PEG-NH $\mathrm{N}_{2}$-treated cells (Figure 1f).

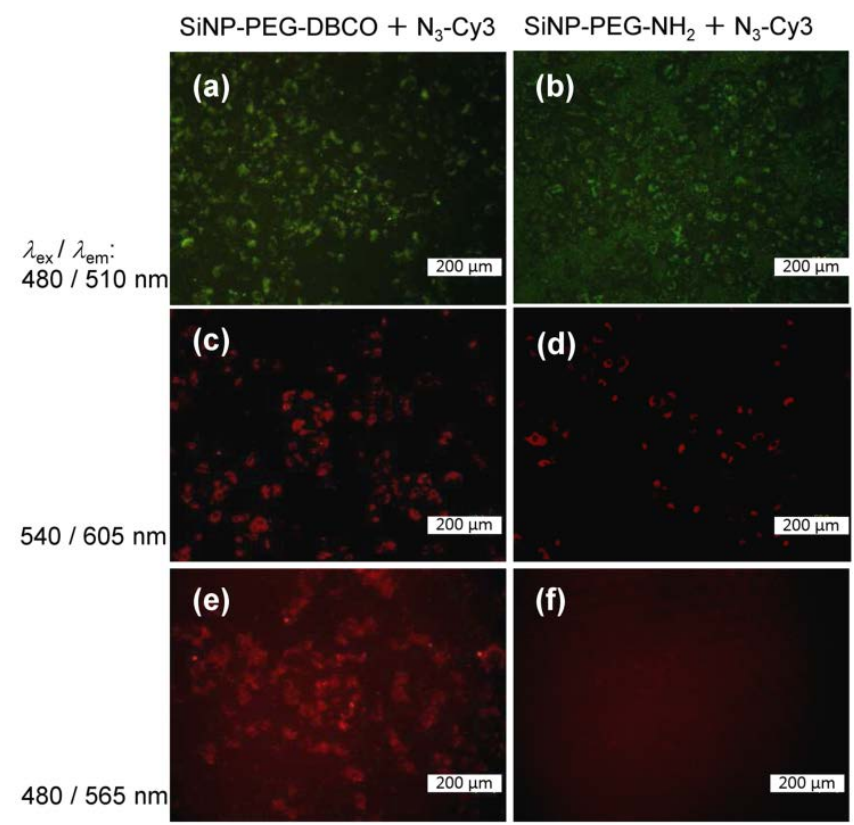

Figure 1. Fluorescence microscope images of A549 cells incubated with (a, c, e) SiNP-PEG-DBCO or (b, d, f) SiNP-PEG-NH2 $(1.0 \mathrm{mg} / \mathrm{mL}$ each) for $3 \mathrm{~h}$, washed with medium buffer, then further incubated in the presence of $\mathrm{N}_{3}-\mathrm{Cy} 3(1 \mathrm{mM})$ for $30 \mathrm{~min}$. Fluorescence images of the cultured cells were obtained by using (a, b) a fluorescein filter combination, (c, d) a Cy3 filter combination, and (e, f) a FRET filter combination.

The surface of SiNPs was easily modified by other azide compounds, such as 4-azidoaniline and 
4-azidobenzoic acid, as judged by the changes in the surface potentials of SiNPs before and after the conjugation (Table S1, Supporting Information).

We then synthesized an azido-modified lipid with the aim of switching the affinity of NPs toward the plasma membrane upon intracellular click modification. Phosphatidyl azidoethanol (PAE) (Figure 2) was obtained from phosphatidyl ethanolamine (PE) by the phospholipase-D catalytic reaction. ${ }^{[30]}$ It has been suggested that components of phosphatidyl lipids are asymmetrically distributed between the inside and outside of the cell membrane and that PE is mainly located inside the membrane. ${ }^{[31]}$

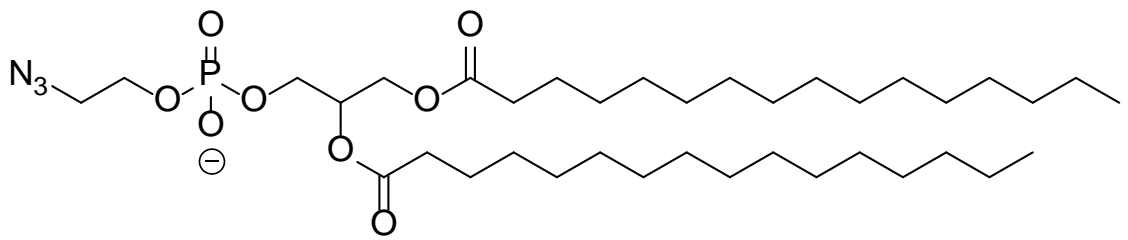

Figure 2. Chemical structure of PAE.

To confirm that click modification of SiNP-PEG-DBCO with PAE improves the affinity of the NP toward the cell membrane, SiNP-PEG-DBCO was pretreated with PAE and then A549 cells were exposed to the resulting conjugates. As expected, localization of SiNPs on the surface of the cell membrane was clearly observed (Figure S5, Supporting Information). Modification was then examined in situ by adding PAE (1 mM) to SiNP-PEG-DBCO-incorporated A549 cells and incubating for $3 \mathrm{~h}$ (Figure 3). Before the click modification, green fluorescent SiNP-PEG-DBCO was observed to be present inside the cells, most likely in lysosomes (Figure S3, Supporting Information). Upon addition of PAE, translocation of SiNPs to the surface of the plasma membrane was observed to take place in a few hours (Figure 3a and Movie S1, Supporting information); the fluorescence then gradually disappeared over $24 \mathrm{~h}$. In contrast, when SiNPs without DBCO (SiNP-PEG-NH${ }_{2}$ ) were employed, no remarkable effects were observed (Figure 3b). In addition, no effects on the apparent intracellular behavior of the SiNP-PEG-DBCO-pretreated cells were 
observed upon exposure to PE and phosphatidyl choline (PC), supporting the conclusion that translocation was induced by PAE (Figure S6, Supporting Information). It should be noted that PAE did not show any remarkable toxicity (Figure S7, Supporting Information).

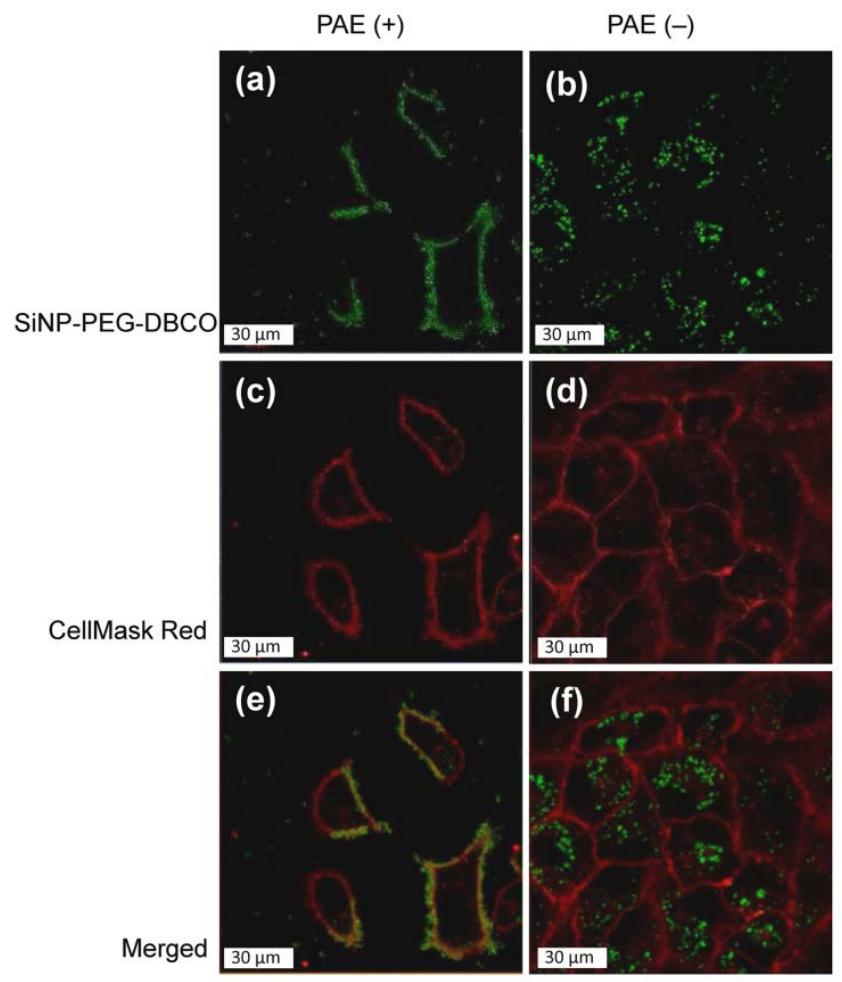

Figure 3. Fluorescence microscope images of A549 cells incubated with SiNP-PEG-DBCO (1.0 mg / $\mathrm{mL}$ ) for $3 \mathrm{~h}$, washed with medium buffer, then further incubated (a, c, e) in the presence or (b, d, f) in the absence of PAE (1 mM) for $3 \mathrm{~h}$. Green fluorescence is from SiNPs. (c, d) The plasma membrane was stained with the red membrane dye CellMask Dark Red (red).

The same experiment was also conducted at a low temperature $\left(4^{\circ} \mathrm{C}\right)$ to observe the effects of click modification under conditions that could suppress energy-dependent endo/exocytotic processes (Figures S8 and S9, Supporting Information). ${ }^{[32,33]}$ Again, colocalization of SiNPs on the cell membrane was observed, implying that PAE-modified SiNPs are predominantly localized on the inside surface of the cell membrane. It is still unclear how PAE contributes to the translocation. 
According to previous studies and to our results, incorporated SiNPs are enclosed into early endosomes, then they mature mainly into late endosomes, then into lysosomes, and then they are finally transported to the cell membrane for excretion. ${ }^{[19,34]}$ Therefore, PAE that fused with the plasma membrane could trap SiNP-PEG-DBCO during the excretion processes. As shown in the preliminary experiment described above, if SiNPs are aligned predominantly on the inside surface of the plasma membrane, our strategy might be used as a new technique for engineering inside and outside surfaces asymmetrically.

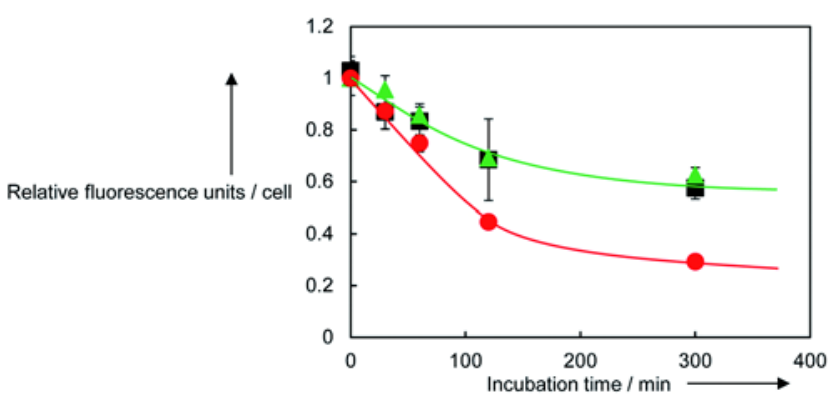

Figure 4. Time-dependent excretion profiles of SiNPs from A549 cells (घ) before and after the addition of $(\bullet)$ PAE or $(\mathbf{\Delta})$ PE (1 mM each) obtained by the quantitative analysis of fluorescence intensity from SiNPs inside the cells as measured using a flow cytometer. Relative fluorescence intensity was determined based on the fluorescence intensity from the cells without any additives.

By using flow cytometry to monitor the fluorescence intensity of the SiNP-incorporated A549 cells after the addition of PAE, time-course profiles of excretion were obtained as shown in Figure 4. Interestingly, an increase in the rate of excretion was clearly observed upon addition of PAE, whereas in the absence of any additive, SiNPs were gradually excreted from the cells, as has previously been reported. ${ }^{[34]}$ Previous studies have suggested that externally added cholesterols that are involved in the regulation of exocytosis could affect the rate of clearance of NPs; ${ }^{[35]}$ on the other hand, PAE might physically control the translocation of SiNPs by anchoring SiNPs on the membrane. The addition of PE had almost no effect on the time course of excretion, which supports the 
conclusion that click modification by PAE increased the affinity of the modified SiNPs toward the plasma membrane, resulting in an increased chance of SiNP excretion.

It has been demonstrated that the zeta potential of engineered NPs could affect the interaction between cell membranes and NPs because of their electrostatic interactions, ${ }^{[36,37]}$ but such effects have not been studied in detail for the excretion. ${ }^{[35]}$ Given that such electrostatic interaction could be neutralized by absorption of proteins on the surface of NPs during the intracellular processes, ${ }^{[38,39]}$ it would be desirable to generate specifically modified surfaces in situ for investigation. Thus, we conducted flow cytometry experiments to study the effects of other azido-modifiers, such as negatively charged carboxylic acid (4-azidobenzoic acid), positively charged amine (4-azidoaniline), and electrostatically neutral compounds (phenyl azide and 2-azidoethanol), on the rate of excretion (Figure S10, Supporting Information); however, the effects were relatively small compared with those recorded using PAE. At this point, the amount of azide that is incorporated into living cells is not clear. Nevertheless, our click strategy is a useful way to evaluate the potential application of NPs with various types of surface modifiers as DDS.

In summary, we have demonstrated that the surface modification of SiNPs with phospholipids inside living cells by utilizing click chemistry can induce localization of the SiNPs on the plasma membrane, and enhance excretion of SiNPs from the cells. This strategy is expected to be useful for investigating the effects of the surface chemical structures of nanoparticles on the processes involved in their excretion from within cells. Another application of click conversion would be sequential delivery of nanoscale materials to multiple target organs by combinations of bioorthogonal coupling reactions after the NPs are incorporated into the cells.

[1] X. Michalet, F. F. Pinaud, L. A. Bentolila, J. M. Tsay, S. Doose, J. J. Li, G. Sundaresan, A. M. Wu, S. S. Gambhir, S. Weiss, Science 2005, 307, 538-544. 
[2] N. L. Rosi, C. A. Mirkin, Chem. Rev. 2005, 105, 1547-1562.

[3] R. Weissleder, Science 2006, 312, 1168-1171.

[4] R. C. Somers, M. G. Bawendi, D. G. Nocera, Chem. Soc. Rev. 2007, 36, 579-591.

[5] C. Kim, S. S. Agasti, Z. Zhu, L. Isaacs, V. M. Rotello, Nature Chem. 2010, 2, 962-966.

[6] B. Kim, G. Han, B. J. Toley, C. -K. Kim, V. M. Rotello, N. S. Forbes, Nature Nanotechnol. 2010, 5, 467-472.

[7] J. Rejman, V. Oberle, I. S. Zuhorn, D. Hoekstrar, Biochem J. 2004, 377, 159-169.

[8] J. P. Ryman-Rasmussen, J. E. Riviere, N. A. Monteiro-Riviere, Nano Lett. 2007, 7, 1344-1348.

[9] M. Lundqvist, J. Stigler, G. Elia, I. Lynch, T. Cedervall, K. A. Dawson, Proc. Natl. Acad. Sci. 2008, 105, 14265-14270.

[10] E. C. Cho, J. Xie, P. A. Wurm, Y. Xia, Nano Lett. 2009, 9, 1080-1084.

[11] C. M. Niemeyer, Angew. Chem. Int. Ed. 2001, 40, 4128-4158; Angew. Chem. 2001, 113, 4254-4287..

[12] E. Katz, I. Willner, Angew. Chem. Int. Ed. 2004, 43, 6042-6108; Angew. Chem. 2004, 116, 6166-6235.

[13] D. Liße, V. Wilkens, C. You, K. Busch, J. Piehler, Angew. Chem. Int. Ed. 2011, 50, 9352-9355; Angew. Chem. 2011, 123, 9524-9527.

[14] S. A. Mackowiak, A. Schmidt, V. Weiss, C. Argyo, C. von Schirnding, T. Bein, C. Bräuchle, Nano Lett. 2013, 13, 2576-2583.

[15] C. Wu, Y. Jin, T. Schneider, D. R. Burnham, P. B. Smith, D. T. Chiu, Angew. Chem. Int. Ed. 2010, 49, 9436 -9440; Angew. Chem. 2010, 122, 9626 -9630.

[16] N. Lewinski, V. Colvin, R. Dreze, Small 2008, 4, 26-49.

[17] H. F. Krug, P. Wick, Angew. Chem. Int. Ed. 2011, 50, 1260-1278; Angew. Chem. 2011, 123, 
$1294-1314$

[18] Y. Teow, P. V. Asharani, M. P. Handec, S. Valiyaveettil, Chem. Commun. 2011, 47, 7025-7038.

[19] R. Sakhtianchi, R. F. Minchin, K.-B. Lee, A. M. Alilany, V. Serpooshan, M. Mahmoudi, Adv. Colloid Interface Sci. 2013, 201 -202, 18-29.

[20] M. F. Debets, S. S. van Berkel, J. Dommerholt, A. J. Dirks, F. P. J. T. Rutjes, F. L. van Delft, Acc. Chem. Res. 2011, 44, 805-815.

[21] J. C. Jewett, C. R. Bertozzi, Chem. Soc. Rev. 2010, 39, 1272-1279.

[22] P. V. Changa, J. A. Preschera, E. M. Slettena, J. M. Baskina, I. A. Millera, N. J. Agarda, A. Loa, C. R. Bertozzi, Proc. Natl. Acad. Sci. USA 2010, 107, 1821-1826.

[23] X. Ning, J. Guo, M. A. Wolfert, G. -J. Boons, Angew. Chem. Int. Ed. 2008, 47, 2253-2255; Angew. Chem. 2008, 120, 2285-2287.

[24] S. N. Goonewardena, H. Zong, P. R. Leroueil, J. R. Baker, Jr., ChemPlusChem 2013, 78, 430-437.

[25] H. Koo, S. Lee, J. H. Na, S. H. Kim, S. K. Hahn, K. Choi, I. C. Kwon, S. Y. Jeong, K. Kim, Angew. Chem. Int. Ed. 2012, 51, 11836-11840; Angew. Chem. 2012, 124, 12006-12010.

[26] W. Stober, A. Fink, E. Bohn, J. Colloid Interface Sci. 1968, 26, 62-69.

[27] L. Tang, T. M. Fan, L. B. Borst, J. Cheng, ACS Nano 2012, 6, 3954-3966.

[28] Y. Chen, Y. Zhang, Anal. Bioanal. Chem. 2011, 399, 2503-2509.

[29] T.-J. Yoon, K. N. Yu, E. Kim, J. S. Kim, B. G. Kim, S.-H. Kim, B.-H. Sohn, M.-H. Cho, J.-K. Lee, S. B. Park, Small. 2006, 2, 209-215.

[30] M. Dippe, C. Mrestani-Klaus, A. Schierfhorn, R. Ulbrich-Hofmann, Chem. Phys. Lipids, 2008, 152, 71-77.

[31] A. Zachowski, Biochem. J. 1993, 294, 1-14 
[32] J. Panyam, V. Labhasetwar, Pharm. Res. 2003, 20, 212-220.

[33] Y. Wang, Q. Wu, K. Sui, X. -X. Chen, J. Fang, X. Hu, M. Wu, Y. Liu, Nanoscale, 2013, 5, 4737-4743.

[34] R. E. Yanes, D. Tarn, A. A. Hwang, D. P. Ferris, S. P. Sherman, C. R. Thomas, J. Lu, A. D. Pyle, J. I. Zink, F. Tamanoi, Small 2013, 9, 697-704.

[35] C. Y. Dombu, M. Kroubi, R. Zibouche, R. Matran, D. Betbeder, Nanotechnol. 2010, 21, 355102.

[36] G. M. Goodman, C. D. McCusker, T. Yilmaz, V. M. Rotello, Bioconjugate Chem. 2004, 15, 897-900.

[37] R. R. Arvizo, O. R. Miranda, M. A. Thompson, C. M. Pabelick, R. Bhattacharya, D. Robertson, V. M. Rotello, Y. S. Prakash, P. Mukherjee, Nano Lett. 2010, 10, 2543-2548.

[38] I. Lynch, K. A. Dawson, Nano Today 2008, 3, 40-47.

[39] A. Mukhopadhyay, C. Grabinski, A. R. M. Nabiul Afrooz, N. B. Saleh, S. Hussain, Appl. Biochem. Biotechnol. 2012, 167, 327-337. 
(Table of contents graphic with text)

Click Strategy for Fast Excretion of Nanoparticles from Living Cells. Silica nanoparticles with cyclooctyne structure on the surface were synthesized for click modification with azidophospholipids in living cells. Click conversion of the surface groups induced localization of nanoparticles on the cell membrane and enhanced excretion of nanoparticles from the cells.

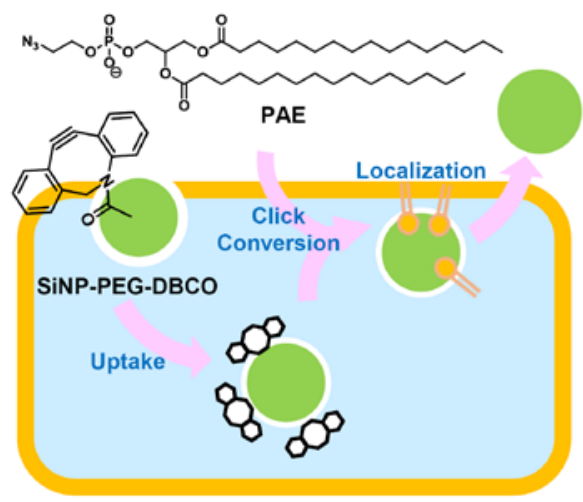

